\title{
O conhecimento pertinente à relação família e educadores da infância: a dialógica da responsabilidade
}

\section{Knowledge related to family and childhood educators relationship: the dialogic of responsibility}

\author{
1 Marina Patrício de Arruda profmarininh@gmail.com \\ 2 Fabiani Aparecida Lourenço Silveira Albuquerque \\ 3 Izabel Cristina Feijó de Andrade
}

\footnotetext{
1 Universidade do Planalto Catarinense UNIPLAC

2 Prefeitura Municipal de Lages

3 Universidade São José - USJ
}

\section{Resumo}

Este artigo teve por base uma dissertação de mestrado em Educação que objetivou compreender as relações entre família e educadores da infância, espaço propício à construção de um conhecimento pertinente à educação infantil. De abordagem qualitativa, a pesquisa analisou entrevistas com representantes de 8 famílias e duas educadoras de um Centro de Educação Infantil da Serra Catarinense e os dados colhidos para a pesquisa foram discutidos por meio da análise textual discursiva. Os resultados obtidos contribuíram para a reflexão sobre as relações construídas no espaço de convivência de educadores da infância e indicam o compartilhamento de responsabilidades como um conhecimento pertinente: a dialógica como unidade entre duas lógicas que necessitam uma da outra, ao mesmo tempo em que se distinguem se complementam. Concluímos provisoriamente que o sentido dialógico mostra a inexistência da certeza e favorece a compreensão de educadores que se disponham a atuar em meio ao acaso e ao imprevisto da vida.

\section{Palavras-chave:}

Conhecimento pertinente. Família e educadores da infância. A dialógica da responsabilidade.

\begin{abstract}
This article was based on a Master's thesis on Education that aimed to understand the relationships between family and childhood educators, a space conducive to the construction of knowledge relevant to early childhood education. From a qualitative approach, the research analyzed interviews with representatives of eight families and two educators of a Center for Early Childhood Education in Serra Catarinense and data collected for the research were discussed through discursive textual analysis. The results obtained contributed to the reflection on the relationships built in the space of coexistence of childhood educators, and indicate the sharing of responsibilities as a relevant knowledge: dialogic as a unit between two logics that need each other, and, while distinguishing themselves, complement each other. We tentatively conclude that the dialogical sense shows the inexistence of certainty, and favors the understanding of educators who are willing to act in the midst of chance and unpredictability.
\end{abstract}

\section{Keywords:}

Relevant knowledge. Family and childhood educators. The dialogic of responsibility.

\section{Como você deve citar?}

ARRUDA, Marina Patrício de; ALBUQUERQUE, Fabiani Aparecida Lourenço Silveira; ANDRADE, Izabel Cristina Feijó de. O conhecimento pertinente à relação família e educadores da infância: a dialógica da responsabilidade. Cadernos UniFOA, Volta Redonda, n. 40, p. 73-82, agosto 2019. 
O conhecimento pertinente à relação família e educadores da infância:

a dialógica da responsabilidade

\section{INTRODUÇÃO}

A pesquisa aqui apresentada sintetiza o processo de construção de uma dissertação de mestrado que incluiu um estudo teórico sobre a relação sistêmica entre família e educadores no espaço da educação infantil. Partimos do pressuposto de que há um conhecimento pertinente que permeia essa relação. Seguimos o alerta de Morin (2011) ao sinalizar que o conhecimento descoberto nessa relação pode produzir cegueiras e enganos ou mesmo gerar certezas que podem separar e dividir as responsabilidades partilhadas pela família e educadores da educação infantil, pois dialogam num contexto de experiências de modo a garantir o desenvolvimento integral da criança. Acreditamos ser essa uma relação sistêmica com funções antagônicas e complementares que nos desafiam a repensar a complexidade dessa relação.

Assim, o objetivo deste estudo foi compreender as relações entre família e os educadores de uma instituição de educação infantil, espaço propício à construção de um conhecimento pertinente.

Na busca por uma articulação sistêmica, nos associamos às ideias que Morin (2011) propõe sobre a necessidade de orientar para a construção de um conhecimento pertinente, aquele contextualizado e pleno de significado. 0 conhecimento pertinente contextualiza as informações e se opõe à fragmentação das relações. O compartilhamento de responsabilidades no contexto da educação infantil pode fazer com que o diálogo religue dados que não podem seguir isolados, configurando um conhecimento não contextualizado "uma visão estritamente formal do conhecimento" (MORIN, 2007, p. 73).

O estudo, pautado nas ideias do autor acima mencionado, encontrou subsídios para compreender a complexidade da relação entre os educadores da infância e família, na perspectiva dos saberes necessários à educação compartilhada, na qual os conhecimentos pertinentes estão relacionados e se complementam.

Aqui justificamos a necessidade da coexistência entre lógicas binárias; de um lado as famílias e, de outro, educadores que, pela possibilidade de compartilhamento e diálogo mútuo para educar e cuidar, se destacam como educadores da infância. Para Andrade (2017, p. 59), [...] a responsabilidade e a autonomia são essenciais, pois todos os envolvidos são corresponsáveis pelo trabalho e pelas escolhas ao longo do desenvolvimento deles. Assim, o território da educação infantil constitui um ambiente propício a reflexões que permitam romper com a dualidade corpo/mente, ser e fazer para a constituição de práticas pedagógicas inovadoras e significativas. Nossas vivências como educadores da infância retroalimentam nossas experiências no contexto educacional no qual vivemos.

\section{PERCURSO METODOLÓGICO DO ESTUDO}

A metodologia, segundo Morin (2011), é o método que nos permite conhecer o conhecimento, lembrando que não existe um método fora das condições do sujeito aprendiz (MORAES, LA TORRE, 2006, p. 153). Também não é um acontecimento que já está previamente sabido sua conclusão, é um percurso a ser caminhado, sempre aberto a novos olhares e concepções, proporcionando novas descobertas que podem trazer consigo acertos e equívocos, porém nada a ser descartado, tudo deve ser valorizado. No pensamento ecossistêmico, alguns princípios metodológicos precisam ser considerados como: intersubjetividade, complexidade, incerteza, multidimensionalidade e transdisciplinaridade.

Ao considerar a intersubjetividade, deixamos aflorar nossa percepção sobre a realidade da biologia humana, pois não existe uma realidade independente do pesquisador. Sendo assim, pesquisador e objeto observado modificam-se mutuamente. Interações e ações mútuas e recíprocas propiciam o surgimento de um novo sistema, uma unidade complexa. 
A abordagem da pesquisa foi qualitativa em que contamos, para este artigo, das análises das entrevistas realizadas com a participação de representantes de 8 famílias e duas (2) educadoras de um centro de educação infantil de um município da Serra Catarinense. Essa pesquisa foi aprovada pelo Comitê de Ética em Pesquisa (CEP), conforme parecer número 2.049.350 e os dados colhidos foram discutidos por meio da análise textual discursiva. Ao iniciar as entrevistas, deparamo-nos com um campo minado e surpreendente, no qual ingressamos com cautela, propondo objetivo às entrevistadas. Observamos que, em seguida, as representantes das famílias se entusiasmaram e demonstraram bastante desejo em contribuir com o trabalho. Para garantir o sigilo em pesquisa, as nomeamos de M1, M2, subsequentemente, e as educadoras, de P1 e P2.

\section{O QUE É UM CONHECIMENTO PERTINENTE?}

Morin (2011) vê na educação um problema universal e complexo, entretanto a fragmentação dos saberes e da desunião dos conhecimentos acaba por simplificá-la por não permitir a convivência de olhares multidisciplinares, transversais, multidimensionais, transnacionais, globais e planetários. Para que o conhecimento seja pertinente, é preciso que ele faça sentido.

O contexto precisa ser resgatado para dar sentido ao todo, uma vez que, ao considerar somente as partes, isso não é possível, pois podemos incorrer no erro e ilusão equivocadamente. "Para ter sentido, a palavra necessita do texto, que é o próprio contexto, e texto necessita do contexto ao qual se enuncia" (MORIN, 2002, p.36).

Somos nós a parte de um todo e carregamos um pedaço desse todo. Isso ocorre também com nossas crianças, que trazem no gene traços físicos ou psíquicos e, como cidadãos de direito, trazem as vivências, saberes, valores que são parte integrante do todo e, por isso, faz-se necessária uma contextualização multidimensional. Portanto, o conhecimento pertinente é aquele que considera em sua constituição os princípios básicos da complexidade e leva em conta todas as dimensões que compõem a criança na sua inteireza.

Em se tratando do sistema educacional, o paradigma da "simplificação" nos fez reduzir o que é complexo do simples. Esse ponto de vista ainda fragmenta nosso conhecimento e evita o conhecimento do complexo. É preciso estar alerta para o perigo da possessão pelas ideias: nós as possuímos, mas elas também nos possuem. Então, como não ser possuído por ideias paralisantes? Como rever conceitos e paradigmas educacionais?

Morin (2011) vê na educação um problema universal, devido à fragmentação dos saberes e da desunião dos conhecimentos que acaba por torná-los complexos, sem nos permitir perceber a existência de adversidades multidisciplinares, transversais, multidimensionais, transnacionais, globais e planetários. Nessa inadequação, tornam-se os grupos invisíveis e desunidos. Para que o conhecimento seja pertinente, a educação tem que torná-los evidente.

\section{POR UMA EDUCAÇÃO INFANTIL INTEGRAL/SISTÊMICA}

A instituição de educação infantil também se configura como um sistema que se articula ao apoio das famílias com crianças pequenas. Para muitos educadores, pensar no cuidado e na educação das crianças pequenas, nesse contexto dinâmico e complexo, implica em analisar as relações familiares sistêmicas. Acreditamos que a participação da criança em ambientes educativos fora de casa repercute nas relações que se estabelecem no interior da família, em suas práticas educativas, bem 
O conhecimento pertinente à relação família e educadores da infância:

a dialógica da responsabilidade

como nas concepções de infância, família e educação que orientam essas práticas e essas relações (ARAÚJO, 2006, p.122).

Porém, é importante frisar também que outro elemento balizador desse processo foi a reflexão de que as instituições educativas não podem abrir mão da sua tarefa de contribuir efetivamente com a construção do conhecimento pelas crianças, e, portanto, não devem nem se transformar numa continuidade da família, em um segundo lar, nem tentar substituir essas famílias na ausência dela.

A instituição de educação infantil imagina que pode se estruturar, para seus alunos, de forma que compense a falta da família. Como se isso fosse possível... não é, e ponto final. A pior consequência desse rumo que a escola tomou é que, desse modo, os alunos ficam carentes de família e de escola também. (FARACHE, 2007, p. 135, grifo nosso)

Para tanto, é fundamental que família e educadores da infância troquem ideias, no sentido de se complementarem em relação às tarefas de cada uma. E ainda mais, é de extrema importância que ambas família e instituição de educação infantil - reconheçam o valor e a importância que cada uma tem na vida e na formação da criança e se respeitem mutuamente. São sistemas independentes e complementares.

Concordamos que "as relações entre a família e o centro educativo devem proporcionar que os pais e as famílias possam compreender, aceitar e valorizar a tarefa educativa da escola" (FARACHE, 2007, p.151). Sendo a instituição de educação infantil uma organização social, apresenta uma unidade própria que lhe caracteriza, enquanto única, mas suas relações e interações se co-constroem com outros sistemas com quem está continuamente em interação e comunicação. Esses sistemas se produzem e produzem a instituição de educação infantil tal como ela é formando um holograma.

Assim, a comunicação, nesse complexo institucional, é gerida de forma centralizada e se articula com diferentes sistemas que comunicam continuamente entre si. Assim, a instituição de educação infantil pode ser considerada como um sistema aberto e interativo com diferentes sistemas que são essenciais para a sua própria existência. A abordagem sistêmica na instituição de educação infantil requer o entendimento das 'relações entre as relações'. Dessa forma, é preciso observar que a família e a instituição de educação infantil têm funcionamentos parecidos e podem ser definidas como sistemas abertos sujeitos à troca, porque se comportam como organização composta por diferentes sistemas auto organizados, mantendo uma autonomia e identidades próprias.

\section{AUTONOMIA E DEPENDÊNCIA NO SISTEMA DA EDUCAÇÃO INFANTIL}

O primeiro questionamento feito às professoras e aos representantes das famílias foi sobre o papel da educação infantil. Apesar de apresentarem perspectivas diferentes, percebemos certa complementaridade. Esses conhecimentos são pertinentes na medida em que destacam a necessidade de se dar autonomia e de se desejar que a criança seja um cidadão de direitos. Os depoimentos a seguir retratam essa realidade: "É educar, é transformar cidadão crítico, reflexivo, pensante aí na educação infantil e é trabalhar bastante autonomia" (P1) (sic); "Então na educação infantil, você tem que ter um, um, um cuidado [....] um trabalho lúdico, né? Onde é... onde abrange brincadeiras e coisas com as crianças" (P2) (sic).

Varela (1989, p. 7) afırma que a "autonomia [...] representa a criação, a afirmação da sua própria identidade, a regulação interna, a definição de interior". Nesse contexto, fazer referência à autonomia dos sistemas e, nesse caso, da criança, conduz-nos ao conceito de sistemas autopoiéticos em que a criança se produz a si própria, produzindo o próprio contexto do sistema da instituição. E, quando essa relação se faz pela comunicação lúdica, proporciona prazer, atenção, contemplação e cuidado. 
Quanto mais rica é a consciência, mais ricas são as liberdades possíveis. A consciência, emergente das tantas possessões possuídas, de tantas dependências produtoras de autonomia, metaponto de vista reflexivo de si sobre si, de conhecimento do conhecimento, é a condição da pertinência da escolha e da decisão, enfim, do valor moral e intelectual da liberdade humana. (MORIN, 2003, p. 280)

Nesse sentido, as educadoras da infância estão no caminho de um entendimento que destaca que a "instituição de educação infantil tem um papel bem importante" (P1), para o desenvolvimento da autonomia das crianças pequenas, quando optam pelo desenvolvimento da autonomia por meio de um processo de auto-organização. Essa capacidade possibilita que a criança produza dentro do sistema institucional uma modificação em função de condições externas e internas propostas pelos sistemas maiores. Essa possibilidade de organizar a sua própria organização confere às crianças autonomia e assegura-Ihe certa continuidade e individualidade, processo que se articula ao conceito de autopoiesis, cunhado por Maturana, (1997) que se fundamenta na ideia de que os seres vivos em seu funcionamento produzem a si próprios.

A complexidade da situação social da infância contemporânea clama o estabelecimento e uma cultura de reconhecimento das crianças em sua alteridade, a partir do respeito aos seus direitos, desejos, especificidades, e à sua participação, indicando que a construção da cidadania ativa das crianças se constitui um passo significativo no caminho da construção de outro mundo possível a partir do que estamos vivendo, das ações e relações cotidianas: um mundo mais democrático e justo para todos, inclusive para as crianças. (CASTODI, 2011, p.50)

A complexidade das relações que se estabelecem nesse contexto pode alterar o encaminhamento de ações tanto positivamente quanto negativamente. Do ponto de vista da complexidade, a instituição de educação infantil é considerada um sistema aberto composto por diferentes sistemas em permanente comunicação e influência mútua. Essa percepção sistêmica da família e da instituição de educação infantil diz respeito a uma reforma do pensamento que conduz a um conhecimento pertinente que percebe e concebe o contexto, o multidimensional e o complexo (MORIN, 2002).

Um apontamento de (P2) que nos chamou a atenção foi em relação às famílias se fazerem presentes na instituição, pois, para a entrevistada, a presença, interação e comunicação são importantes: "[...] até porque a criança eu acho que se sentiria assim, mais é ... importante, ou que os pais se importam com elas, porque talvez a revolta que aconteça lá nos anos seguintes, seja dessa falta de convívio sabe? Essa falta de atenção [...]". (sic).

Na perspectiva das crianças e das infâncias e sob o ponto de vista da luta pela emancipação social, emergem alguns questionamentos: qual o lugar da infância, quando pensamos na reforma do pensamento? Como lutar para o reconhecimento das especificidades das crianças perante os adultos e, ao mesmo tempo, reivindicar que ambos sejam vistos como diferentes e complementares, com autonomia, voz e vez?

Uma das entrevistas ainda aponta a necessidade da família se organizar, uma vez que possui mais um membro, e se inserir no conjunto de atividades ou responsabilidades a serem partilhados pelo grupo. $\mathrm{P} 2$ ressalta que

[...] quando você se disponibiliza a ter um filho, você tem que pensar lá na frente já achar um tempinho para eles [...] poucas famílias, poucos pais, poucas famílias ficam com os filhos, então pra mim, não é disponibilidade de tempo, é [...] falta de compromisso e de vontade (sic).

Esse é um olhar próprio de uma educadora de infância que, a partir de sua história de vida pessoal e profissional, construiu uma ideia sobre o dito compromisso familiar. Desse modo, propomos uma análise de possíveis distorções e perturbações da comunicação entre as famílias e educadores da infância e suas consequências para os sistemas e seus pares. Uma dessas é quando família e 
instituição não se comunicam ou não se envolvem relacionalmente. A falta de troca de informações prejudica a articulação em que é necessário o compromisso da comunicação.

Entre as contradições dos sistemas, encontramos algumas resistências nos contextos específicos que podem ser considerados, por um, sistema com negligência e por outro, não. Para Castodi (2011, p. 36), "as crianças têm sido negligenciadas a partir da precarização de suas condições de vida, quanto à ênfase do direito dos adultos sobre elas". Portanto, apesar da compreensão dos problemas relacionados à lógica social de uma sociedade que trabalha em prol dos adultos, as crianças passam a infância invisíveis aos olhos de quem as julgam, sem de fato as entenderem.

No momento em que interpelamos duas professoras, inquirindo sobre o que é importante para que haja um bom relacionamento entre a família e a instituição de educação infantil, ambas convergiram ao apontar o diálogo como estratégia principal.

Para nós, pesquisadoras, o diálogo se apresenta como ferramenta essencial e primordial para uma boa relação na construção de um conhecimento pertinente. Faz-se importante a prática de uma comunicação aberta, ainda mais se tratando da educação infantil. Assim, consideramos o diálogo como um processo recíproco de co-construção, de troca de experiências e não apenas transmissão de informação. É pelo diálogo que famílias e educadores da infância têm a oportunidade de clarificar o sentido e as regras da própria instituição, de modo a possibilitar a construção de "uma representação comum sobre a criança".

Porém $\mathrm{P}(2)$ relatou que a dificuldade dessa relação pode estar na própria instituição (na pessoa do educador) que não demonstra quaisquer interesse e ou acolhimento das famílias das crianças que frequentam aquela escola, como segue: "A própria instituição não dá, a própria instituição [...] aí vem um colega de trabalho, de repente que não gosta muito disso e faz cara feia, ou corta, né? E daí os pais se sentem intimidados e não [...] vão além, entende?" (sic)

Nesse sentido, famílias e educadores da infância acabam não tendo outra opção, a não ser dividir o que sabem sobre suas crianças que ainda não conseguem sozinhas se comunicar verbalmente. Eles trabalham em equipe dando suporte e apoio necessário às necessidades diárias das crianças. $E$, uma vez que isso acontece, se estabelece a confiança entre a família e a instituição de educação infantil, trazendo benefícios em longo prazo para os bebês, foco principal de toda a dedicação. Para Relvas (2006, p.126), essa interface representa uma estrutura relacional entre educadores-família-criança e "concretizam-se na panóplia de escolhas comunicacionais utilizadas por esta estrutura, no quadro restrito dos dois códigos". Essa relação, de acordo com o que observamos, deve ser pautada em respeito mútuo, confiança, e fará bem também, se os envolvidos quiserem dar e receber, entre outras interações, para constituir as bases de um relacionamento.

\section{RESPONSABILIDADES COMPARTILHADAS: FAMÍLIA E INSTITUIÇÃO DE EDUCAÇÃO INFANTIL}

As famílias que participaram das entrevistas deram suas opiniões sobre o papel da instituição de educação infantil. E os depoimentos das entrevistadas acabaram se complementando, pois manifestaram diversos aspectos inerentes à nossa contemporaneidade, destacando o quão importante é a educação infantil. Alguns depoimentos sinalizaram o apoio dos pais na realização da tarefa de casa, considerando que o espaço escolar "é extensão da educação familiar [...]"(M3). 
Assim, ao mesmo tempo em que a instituição de educação infantil se apresenta aos olhos da família como complementar ao papel educativo, emerge também como "instrumento social de avaliação do desempenho das funções das famílias, embora de modo não explícito" (RELVAS, 2006, p. 114). Algumas famílias apontaram a questão do auxílio no desenvolvimento da criança, que seria o aspecto mais amplo da relação família/instituição, conforme destaca a M4: "[...] auxílio no desenvolvimento da criança [...] o principal que é nos socorrer que a gente precisa trabalhar e tem que ter onde deixar os nossos pequenos" (sic). E outras expressões também vieram firmando a escola como espaço de amparo, colaboração para o trabalho dos pais. Essa compreensão é uma forma de reducionismo e não questiona a lógica clássica que fundamenta o pensamento moderno que controla o discurso e conforma o modo de pensar e interpretar os fenômenos (MORIN, 2000).

Por outro lado, um dos depoimentos revelou que a responsabilidade das famílias é fundamental nessa parceria, de acordo com M7 "[...] não tirando a responsabilidade dos pais, mas, auxiliando nesse desenvolvimento dos nossos filhos". Diante de todas essas falas, não podemos deixar de mencionar que quase todas as famílias se referiram à instituição de educação infantil como parte auxiliar do processo. Pontuaram o compartilhamento de responsabilidades, ou seja, uma instituição complementando o trabalho da outra, pois consideraram que cada uma dessas instituições possui um conhecimento pertinente ao contexto da educação infantil.

Indagamos também sobre o que significa educação integral e, de imediato, o retorno que temos é que diz respeito à permanência da criança durante dia todo na instituição de educação infantil. Uma outra compreensão destacou que a educação integral veio facilitar a vida dos pais que trabalham, dando a chance à continuidade da carreira profissional deles. E outras incluíram também o cuidado e a assistência. Assim, a educação integral é também entendida como socorro às famílias que não têm com quem deixar os seus pequenos.

Convém retomar, então, à ideia de Caetano e Yaegashi (2014, p. 22), "a família e a instituição de educação infantil são contextos de desenvolvimento e aprendizagem e apenas essa constatação deveria bastar e ser suficiente para justificar a necessidade de que escola e família trabalhassem cooperativamente". Sendo assim, para os autores, ambas as instituições têm funções educativas.

Nesse contexto, é preciso um empenho coordenado, sistemático e simultâneo que articule os vários aspectos apresentados e vivenciados pelos dois sistemas. Isso indica a articulação de diferentes atores e saberes para o cuidado e atendimento da criança na sua inteireza. A colaboração entre famílias e educadores da infância torna-se fundamental para o desenvolvimento e também para o desenvolvimento da criança durante o processo da educação infantil.

As famílias entrevistadas ressaltaram a importância dos professores e da instituição em si, conforme os extratos que selecionamos. M7: "a escola em si ela é importante", é importante porque lá tem, tem profissionais" (sic); M1 "a escola que ela frequenta hoje para mim é a escola ideal; eu tô plenamente satisfeita com o Ceim" (sic) ou como acrescenta M6 ao dizer que: "no geral tá excelente assim pelo que acompanho ele aqui". (sic)

Conforme pudemos observar, o grau de satisfação é elevado por parte das famílias pesquisadas, fato que faz com que essa parceria seja benéfica a todos. Mas o que de fato se espera é que família e escola tracem metas articuladas, de modo a propiciar segurança, aprendizagem que fortaleça cidadãos críticos para enfrentar a complexidade de situações que surgem ao longo da vida.

Esse é o tipo de relação almejado nesse contexto, pois harmonia, confiança e cuidado podem promover o desenvolvimento físico, intelectual e emocional da criança. É nesse sentido que a instituição 
de educação infantil pode se tornar um ambiente de promoção de uma educação libertadora, tendo em vista que esse espaço não é isento de intenções.

Indagamos ainda se elas sabiam "o que faz uma professora da educação infantil", e muitos relatos indicaram, de fato, o que essa profissional faz. M8 destacou que "[...] elas cuidam, cuidam com muito amor, com muito carinho [...]"; (M1): "[...] ela constrói valores, [...] constrói conhecimento [...]"; M7 pontuou que "[...] eu acho que uma professora da educação infantil, ela acaba exercendo inúmeras profissões juntos, é como eu disse a ela se desdobra [...] o papel da professora acaba sendo de uma responsabilidade sem tamanho [...]" (sic). M6, mais objetiva destacou: "[...] a função dela digamos é ensinar, é ajudar a criança a ter um desenvolvimento bem bom né pro dia-a-dia [...]" (sic).

Dessa forma, percebemos o quanto a relação escola e família torna-se importante na vida da criança e essa parceria também distingue o papel da educadora infantil.

Por se tratar de importante período da vida educacional das crianças, é que nos preocupamos em ouvir os sentidos das relações que se estabelecem entre famílias e educadores da infância. 0 pensamento complexo torna-se pertinente frente à necessidade de articular, relacionar, contextualizar (MORIN, 2003, p. 38). Esse autor alerta-nos para a valorização da religação de saberes vividos, para que se possa também compartilhar responsabilidades.

Por meio dessas reflexões, podemos dizer que a família e a instituição de educação infantil despontam como instituições essenciais para desencadear os processos de desenvolvimento das crianças, atuando como fomentadoras ou como fontes impeditivas de seu progresso físico, intelectual, emocional e social. E quando há boas relações entre família e instituição de educação infantil, a qual se dá principalmente pela comunicação, há também um melhor resultado em prol da criança. As famílias citaram que há um contato diário e pessoal com a instituição. Segundo M8, "só na escola mesmo, não tenho convivência fora [...]"; para M2: "[...] converso de manhã, e de tarde eu converso à tarde. Então de manhã eu vejo como ele foi na manhã anterior e à tarde eu já vejo na hora, porque daí eu já tenho contato com ela..." (sic); e, M7 destacou: "[...] você entrega ali aí você fala rapidinho [...]" (sic); mas segundo M5: "[...] se precisar conversar com ela a gente tem esse acesso [...] Telefone, contato diário, esses assim né?"(sic).

Esses relatos evidenciaram que as relações se dão efetivamente pela comunicação que Post e Hohmann (2011) apontam, como estratégia, a prática da comunicação aberta, para desempenhar o ponto forte da vivência. A comunicação aberta envolve conversar de forma honesta e direta. "[...] quando se procura nivelar com os outros, tenta-se a todo custo comunicar o que se quer dizer com a maior clareza possível". (POST e HOHMANN, 2011, p. 309)

De acordo com os autores acima, é importante que se tenha uma comunicação aberta, que se fale claramente o que se deseja. Dessa forma, os membros partilharam seus pensamentos e sentimentos, falaram e escutaram respeitosamente uns aos outros. Considerando que a comunicação acontece diariamente, é por meio dessa estratégia que se constitui uma relação forte, segura e facilitadora.

Os participantes da pesquisa lembraram também que se trata de uma relação boa, porque há uma troca respeitosa e sadia. Conforme M2: "[...] é muito bom ele tem muito contato com a gente [...]"; M4: "[...] a minha relação com todo mundo aqui é muito boa [...]"; e M5: "[...] eu vejo uma relação bem sadia, é nunca tive problemas com professoras ou alguma reclamação, então hoje eu vejo uma relação bem sadia assim, uma relação bem construtiva, bem produtiva" ( $\mathrm{sic}$ ). Esses depoimentos reconhecem a importância de relação exitosa entre as referidas instituições. Por outro lado, houve também quem apontasse falhas. M7 relatou: "eu acho assim que acaba voltando a essa questão do tempo, acho que acaba sendo falha, 
por não termos tempo de convivência, dessa relação" (sic). Tal depoimento que sinaliza a importância de se dedicar tempo para firmar as relações entre família e instituição de educação infantil. 0 tempo de permanência diária das crianças na instituição e os acordos estabelecidos com as famílias incluem atividades de cuidado organizadas em função de suas necessidades nas vinte e quatro (24) horas do dia. Isso exige uma programação conjunta com as famílias para divisão de responsabilidades, evitando-se a sobreposição ou a ausência de alguns dos cuidados essenciais (BRASIL, 1988, p. 74).

O pensamento complexo possibilitou nossa compreensão sobre a relação família e educação infantil, ao valorizar a amplitude de saberes e olhares partilhados.

\section{CONSIDERAÇÕES PARA ENCERRAR PROVISORIAMENTE ESSA REFLEXÃO}

As reflexões referentes à compreensão sobre a relação entre família e educadores de uma instituição de educação infantil mostraram a emergência de um espaço propício à construção de um conhecimento pertinente e revelaram depoimentos atenciosos/amorosos, da maneira como as perguntas foram sendo respondidas.

Em meio aos registros, observamos a necessidade de se dar autonomia às crianças e de favorecer a participação das famílias no sistema da educação infantil de modo mais efetivo, considerando que é de forma sistêmica que família e educadores se constituem o corpo de educadores da infância em busca de um conhecimento pertinente à essa relação.

Destacamos como principal resultado dessa reflexão o compartilhamento das responsabilidades para com as crianças que frequentam o centro de educação infantil. Nesse contexto, relações sistêmicas emergem para proporcionar à criança a garantia de seus direitos, em ambos os grupos de convivência que veem no diálogo o ponto fundamental para o desenvolvimento adequado no trabalho com as crianças.

Destacamos algumas dificuldades encontradas no cotidiano dessa relação que, por vezes, impedem o compartilhamento de responsabilidades, como perturbações na comunicação; o olhar reducionista, que impede que a criança possa ser vista por inteiro e não apenas em sua dimensão biológica; e a ideia equivocada de transferência de responsabilidades. Os resultados obtidos contribuíram para a reflexão sobre as relações construídas no espaço de convivência de educadores da infância e indicam o compartilhamento de responsabilidades como um conhecimento pertinente: a dialógica como unidade entre duas lógicas que necessitam uma da outra, ao mesmo tempo em que se distinguem se complementam. O sentido dialógico mostra a inexistência da certeza e favorece a compreensão de educadores que se disponham a atuar em meio ao acaso e ao imprevisto (MORIN, 2002) da vida.

Como instituições e sistemas educativos, a família, a instituição de educação infantil contemporânea e nela os educadores da infância também fazem parte da tessitura cotidiana da sociedade contemporânea. 0 conhecimento pertinente, oriundo de um pensamento complexo, aquele que opera a partir dos princípios da complexidade - princípio do diálogo - desafia os envolvidos a uma nova postura que possibilite religar os saberes de famílias e educadores. Nesse sentido, é preciso compreender, perceber as contradições e as relações que se estabelecem entre essas duas instâncias para, então, religá-las.

Que este estudo possa se constituir em uma reflexão significativa tanto para educadores da infância como para as pessoas envolvidas nos sistemas de cuidar e educar da criança, para que ocorra a valorização e também o compartilhamento do conhecimento pertinente oriundo dessa vivência. Esperamos ainda que este trabalho integre outras reflexões, trazendo outros pontos de exploração que não foram aqui abordados. 
O conhecimento pertinente à relação família e educadores da infância:

a dialógica da responsabilidade

\section{REFERÊNCIAS}

ANDRADE, I. C. F. de; et al. Um currículo pensado e vivido para a criança pequena: uma educação mais natural, divertida e produtiva, 2. ed. São José: ICEP, 2017.

ANDRADE, I. C. F. de. A inteireza do ser: uma perspectiva transdisciplinar na autoformação de educadores. Porto Alegre, 2011.

ARAÚJO, D. S. Infância, família e creche: um estudo dos significados atribuídos por pais e educadoras de uma instituição filantrópica. Tese (doutorado). Goiânia. 2006.

ARRUDA, M. P. 0 professor como mediador de emoções. ETD - Educ. temat. digit. Campinas, SP v.14 n.2 p. 290-303 jul./dez. 2012

CAETANO, L. M.;YAEGASHI, S. F. R. Relação escola e família: diálogos interdisciplinares para a formação da criança. São Paulo: Paulinas, 2014.

CASTODI, G. de A. Cosmopolitismo Infantil: Qual o lugar social das crianças na contemporaneidade? Zero a seis, Florianópolis, v. 13, n. 23, p. 33-51, 2011.

FARACHE, Cláudia da Silva. A relação entre a família e a instituição de educação infantil: descrição reflexiva sobre uma experiência. Tese de doutorado. Natal, 2007.

MARQUES, Circe M. Educação para a paz e educação infantil: um olhar e uma escuta sensível no ambiente educativo. Dissertação de Mestrado. São Leopoldo. 2005.

MATURANA, H. A ontologia da realidade. Belo Horizonte: UFMG, 1997.

MORAES, Maria C.; TORRE, S. Pesquisando a partir do pensamento complexo: elementos para uma metodologia de desenvolvimento ecossistêmico. Revista Educação. PUCRS, no XXIX (1). Porto Alegre, 2006, p.145-172.

MORIN, E. Os sete saberes necessários à educação do futuro. São Paulo: Cortez, 2011.

MORIN, E. Introdução ao pensamento complexo. Tradução de Eliane Lisboa. 3. ed. Porto Alegre: Sulina, 2007.

MORIN, E. . Ciência com consciência. Rio de Janeiro: Bertrand Brasil, 2003.

MORIN, E. A religação dos saberes: o desafio do século XXI. Rio de Janeiro: Bertrand Brasil, 2002.

POST, J.; HOHMANN, M. Educação de Bebés em Infantários: cuidados e Primeiras aprendizagens. 4. ed. Trad. Sara Basía. Lisboa: Fundação Calouste Gulbenkian, 2011.

RELVAS, A. P. 0 ciclo vital da família: perspectiva sistémica. 4. ed. Porto: Edições Afrontamento, 2006.

VARELA, F. Autonomie et connaissance: Essai sur le vivant. Paris: Éditions du Seuil. Varela, F. (1989b). Reflections on the circulation of concepts between a biology of cognition and systemic family therapy. Family Process, 28, 15-24, 1989.(trad.google tradutor) 